\title{
IN ORBIT DEBRIS-DETECTION BASED ON SOLAR PANELS
}

\author{
W. Bauer
}

German Aerospace Center (DLR), Institute of Space Systems, Robert-Hooke-Str. 7, 28359 Bremen, Germany, waldemar.bauer@dlr.de

\section{O. Romberg}

German Aerospace Center (DLR), Institute of Space Systems, Robert-Hooke-Str. 7, 28359 Bremen, Germany, oliver.romberg@dlr.de

\section{A. Pissarskoi}

German Aerospace Center (DLR), Institute of Space Systems, Robert-Hooke-Str. 7, 28359 Bremen, Germany, alexei.pissarskoi@dlr.de C. Wiedemann

Technische Universität Braunschweig, Institute of Aerospace Systems, Hermann-BlenkStr. 23, 38108 Braunschweig, Germany, c.wiedemann@tu-braunschweig.de

\section{P. Vörsmann}

Technische Universität Braunschweig, Institute of Aerospace Systems, Hermann-BlenkStr. 23, 38108 Braunschweig, Germany, p.voersmann@tu-braunschweig.de

\begin{abstract}
The Solar Genarator based Space Debris Impact-Detector (SOLID) currently under development at DLR, has a large impact area and offers high orbital flexibility. Once placed in orbit, it will collect Space Debris (SD) and Micro-Meteoroids (MM) impact data for software validation (e.g. MASTER or ORDEM). The verification of SOLID itself will be based on High-Velocity-Impact testing (HVI-testing) anticipated at the Fraunhofer EMI (Ernst-Mach-Institute for High-Speed Dynamics in Freiburg, Germany). This paper presents the current state of SOLID development. Furthermore the setup of the engineering model as well as corresponding assumptions made in terms of the manufacturing process are presented.
\end{abstract}

\begin{tabular}{|l|l|}
\hline \multicolumn{2}{|l|}{ Abbreviation: } \\
\hline ACS & Attitude Control Subsystem \\
\hline CFRP & Carbon-Fiber-Reinforced Plastic \\
\hline D & Crater Damage Diameter \\
\hline DH & Data Handling subsystem \\
\hline Dh & Hole Diameter \\
\hline DL & Detection Layer \\
\hline DLR & Deutsches Zentrum für Luft- und \\
\hline Rpit & Pit Diameter \\
\hline E-BOX & Electronics Box \\
\hline EPS & Electrical Power Subsystem \\
\hline ESA & European Space Agency \\
\hline EURECA & EUropean Retrievable CAriar \\
\hline H/W & Hardware \\
\hline HST & Hubble Space Telescope \\
\hline HVI & High Velocity Impact \\
\hline LEO & Low Earth Orbit \\
\hline
\end{tabular}

\begin{tabular}{|l|l|}
\hline MASTER & $\begin{array}{l}\text { Meteoroid and Space Debris } \\
\text { Terrestrial Environment Reference }\end{array}$ \\
\hline MM & Micro-Meteoroids \\
\hline ORDEM & Orbital Debris Engineering Model \\
\hline P & Crater Depth \\
\hline P/L & Payload \\
\hline PCB & Printed Circuit Board \\
\hline PV & Photovoltaic \\
\hline S/C & Spacecraft \\
\hline S/G & Solar Generator \\
\hline SA & Solar Array \\
\hline SD & Space Debris \\
\hline SGS & Solar Generator Structure \\
\hline SMD & Surface-Mounted Device \\
\hline SOLID & $\begin{array}{l}\text { Solar Generator based Impact } \\
\text { Detector }\end{array}$ \\
\hline SS & Subsystem \\
\hline TM\&TC & Telemetry and Telecomand \\
\hline
\end{tabular}




\section{INTRODUCTION}

Space missions can be endangered by Space Debris (SD) and Micrometeoroids (MM). Impacting objects can damage or even destroy spacecraft $(S / C)$ or payloads $(P / L)$. The MM population during the year consists of a superposition of a sporadic background flux with a number of seasonally recurring meteoroid streams. However, in contrast to the highly dynamic space debris environment, the annual mean meteoroid environment can be assumed to be static [1]. Space activities over the past 55 years have led the creation of SD. Table 1 gives an overview of the SD situation today. As can be seen, the quantity of the objects increases strongly if the object diameter becomes smaller. The radar catalogue comprises today ca. 16,300 objects, which are mostly tracked by Space Surveillance Network (SSN). Some of the tracked objects are $5 \mathrm{~cm}$ in diameter. By examination of Table 1, it becomes clear that even objects larger than $10 \mathrm{~cm}$ in diameter cannot be fully covered by ground based surveillance systems. Consequently the data concerning smaller objects can be gained only by examination of retrieved $\mathrm{H} / \mathrm{W}$ from space or by on-orbit (in-situ) detectors. To better understand the space environment, ESA had performed post flight impact analysis on retrieved hardware $(\mathrm{H} / \mathrm{W})$ from space. Extensive investigation of damage on solar generators had been performed e.g. on EUropean Retrievable CAriar (EURECA) and Hubble Space Telescope (HST) [8, 9]. The gained understanding on SD can be used to validate the environmental models, like e.g. MASTER. Investigation of retrieved $\mathrm{H} / \mathrm{W}$ can contribute to better understanding of the space environment but they cannot provide the information of impact time and corresponding position on orbit. For these purpose in-situ detectors offer convenient solutions [3].

From systems engineering perspective the prime focus of data acquisition with in-situ detectors for environmenta models validation should focus on millimeter objects down to 100 micron. This is required at least for the following reasons:

- damage to the Spacecraft $(S / C)$ or Payload $(P / L)$ can be expected already from $100 \mu \mathrm{m}$ particle,

- the quantity of the objects in this size range is pretty high and the knowledge of the small objects population in space is rather limited and need to be enhanced for reliable models.

\begin{tabular}{|c|c|c|c|}
\hline 2009 & Size & Quantity & Comments \\
\hline (2) & \multicolumn{3}{|c|}{$\begin{array}{l}\text { Ground based surveillance (normal) } \\
16,300 \text { Objects within radar catalog (some of them ca. } 5 \mathrm{~cm} \text { ) } \\
\text { Ca. } 800 \text { active Satellites } \\
\text { Mission lost in case of collision. }\end{array}$} \\
\hline & $>10 \mathrm{~cm}$ & 29,000 & $\begin{array}{l}\text { Ground based surveillance (limited) } \\
\text { Mission lost in case of collision. }\end{array}$ \\
\hline & $>5 \mathrm{~cm}$ & 60,000 & $\begin{array}{l}\text { Ground based surveillance (limited) } \\
\text { Mission lost in case of collision. }\end{array}$ \\
\hline & $>1 \mathrm{~cm}$ & 700,000 & $\begin{array}{l}1 \mathrm{~cm} \text { object releases energy equivalent to } \\
\text { hand grenade } \\
\text { Mission lost in case of collision. }\end{array}$ \\
\hline & $>1 \mathrm{~mm}$ & 200 million & $\begin{array}{l}\text { Retrieved Surfaces / In-Situ Detectors, } \\
\text { High probability of spacecraft damage in } \\
\text { case of collision. }\end{array}$ \\
\hline & $>100 \mu \mathrm{m}$ & trillions & $\begin{array}{l}\text { Retrieved Surfaces / In-Situ Detectors, } \\
\text { Damage/degradation of spacecraft in case } \\
\text { of collision possible. }\end{array}$ \\
\hline
\end{tabular}

Table 1: Particle size and quantity distribution: data based on [2]

\subsection{Hazard to $S / C$ Arising from Impacting Objects}

Due to a high impact velocity (RoM: $10 \mathrm{~km} / \mathrm{s}$ in LEO), impacting particles in space can cause serious electrical or mechanical damage on spacecrafts or payloads $[4,5]$. Many different parameters need to be considered relating to hypervelocity impact e.g. target and impactor material, shape of the impactor. However, the most important parameters are the diameter and the relative velocity of the impactor. The main hypervelocity impact effects taken from [4] are:

- cratering and ejecta,

- structural damage

- plasma effects

- momentum transfer.

Depending on a mission, these effects could lead to serious disturbances or damage to spacecraft and payloads.

\subsection{SD and MM Data Sources for Model Validation}

The available SD and MM assessment software tools e.g. MASTER or ORDEM use mathematical models to describe the space environment. The validation of these mathematical models is based on measured SD and MM data from $[1,3]$ :

- ground based radar and optical systems,

- space based radar and optical systems,

- retrieved surfaces from space,

- in-situ impact detectors.

In terms of the SD and MM data acquisition for model validation purposes, this paper focuses only on the in-situ impact detection method.

\section{DETECTOR CONCEPT}

\subsection{General Idea}

To close the data gap between the $\mathrm{cm}$ and the $\mu \mathrm{m}$ range of particle size, a new type of impact detector is currently under development at DLR. The knowledge of SD and MM distribution in orbit is essential to realise model validation. The top level requirements for the SD and MM impact detector concept are derived from the following keyissues:

- Mission Duration: shall be long

- Detection Area: shall be large

- Mass, Volume, Power Consumption,

Data Rate: shall be low

- Implementation to S/C : shall be simple

Unlike most conventional detectors (see Figure 1, Figure 2), the proposed new concept makes use of already existing subsystems (SS) of the spacecraft bus and adapt those for impact detection as depicted in Figure 1.

The Electrical Power Subsystem (EPS) and the Attitude Control Subsystem (ACS) are used for data acquisition. The Data Handling subsystem (DH) and Telemetry and Telecommand subsystem (TM\&TC) serves for the data processing and data transfer to Earth. 


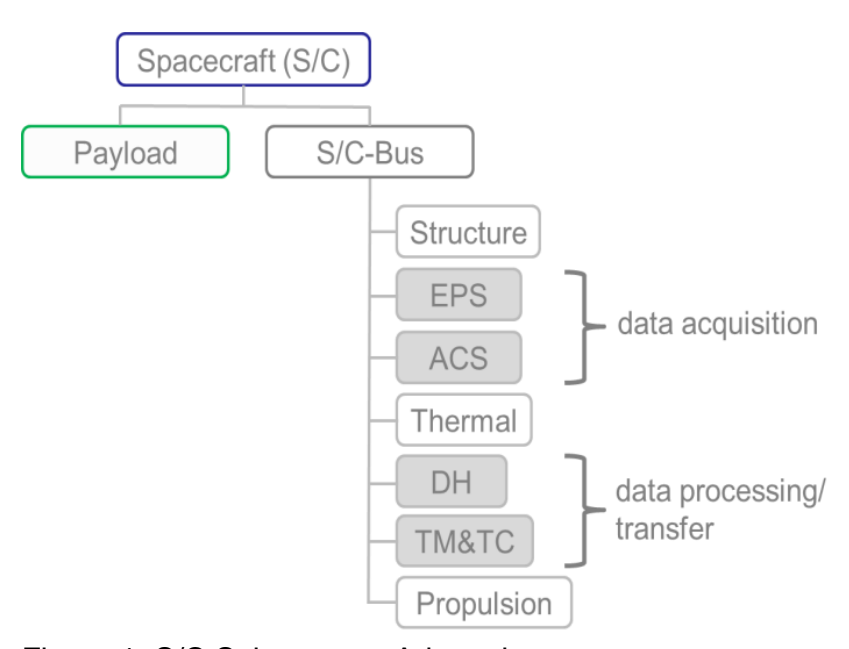

Figure 1: S/C Subsystems Adaptation

\subsection{Functionality}

The Solar Genarator based Space Debris Impact-Detector (SOLID) $[6,7]$ is a large area impact detector which can be flown in any orbit.

Figure 2 illustrates the functional principle of SOLID. The core element of the concept is a solar generator $(\mathrm{S} / \mathrm{G})$ with photovoltaic cells (PV) which fulfils at least three of the defined key-issues:

- $\quad$ long mission duration;

PV-cells-battery is the most common method to supply S/C with energy during entire mission,

- $\quad$ large detection Area;

$\mathrm{S} / \mathrm{G}$ has as a rule a large area to provide the $\mathrm{S} / \mathrm{C}$ with sufficient energy,

- simple implementation to the S/C;

$S / G$ is not an add-on component to the $S / C$ but it has to be adapted to the impact detection purpose.

Furthermore SOLID has an autonomous electronic box (EBOX) which is implemented into the interior of the S/C.

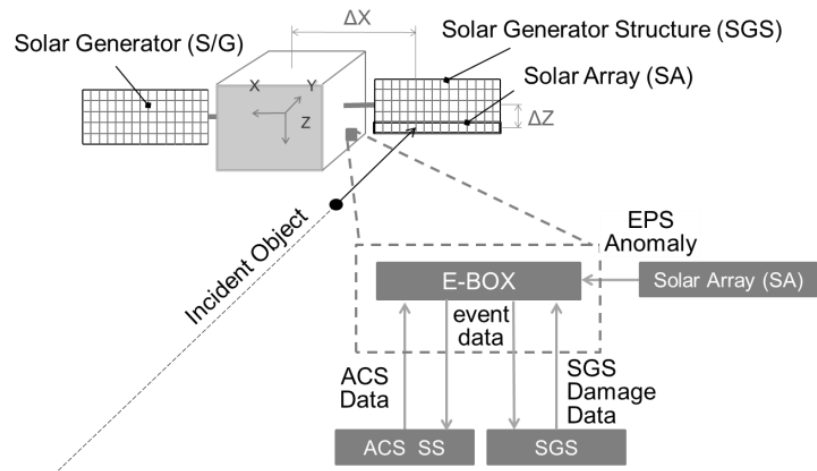

Figure 2: Functional principle of SOLID concept

The incident particle (see Figure 2) which hits the solar cell could lead to an anomaly in power supply. The E-BOX monitors the power SS for these types of events and compares them to the predefined impact disturbance behaviour. Once the anomaly has been identified as an impact, the solar generator structure (SGS) is analysed concerning presence of damage on the SGS. From this analysis the impact location and damage to the SGS, caused by impact, is determined. The latter allows an estimation concerning incident particle diameter (see subsequent chapter). The ACS data is also analysed to ascertain the momentum transfer to the $S / C$ related to $S D$ or MM impacts. Also this data acquisition takes place within a predefined time after the impact. The combination of the known impact position and the particle diameter from SGS analysis with the momentum transfer from ACS SS enables an implication of the particle velocity.

Figure 3 shows the principal adaptation method of the standard SGS for the purpose of impact detection. In comparison to commonly used SG for Space applications, the SOLID concept modifies the insulation layer (e.g. Kapton), which is placed in between solar cell adhesive and the sandwich face sheet. Kapton has excellent thermal insulation and electrical insulation properties and is therefore a common material for $S / G$ s. The SOLID concept integrates two layers of copper lines between the Kapton layers and forms a detection grid. In the case of an impact event the incident particle causes damage which can range from cover glass down to the detection layer and consequently sever the copper lines. In this case number and position of the severed strips can be identified by the detection electronics/software (see Figure 2 EBOX). A diameter estimation of the incoming particle which caused the damage could be made by using known damage equations as seen in [8].

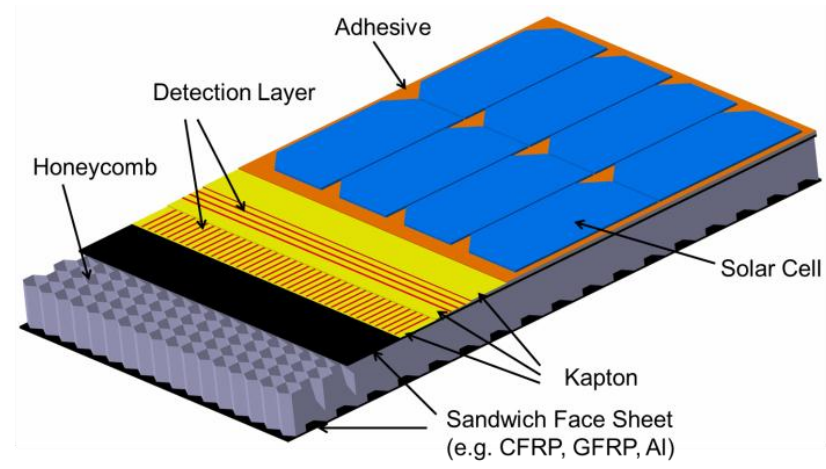

Figure 3: SG adaptation for SOLID concept

\section{CURRENT STATE OF SOLID DEVELOPMENT}

Currently, DLR is in manufacturing process of the previous discussed SOLID detector concept. Once the detector prototype is manufactured, it will be verified by HighVelocity-Impact testing (HVI-test) anticipated at the Fraunhofer EMI (Ernst-Mach-Institute for High-Speed Dynamics in Freiburg, Germany).

According to [7] the top layers setup of SOLID concept (cover glass down to the Kapton layer) is similar to EURECA and HST solar generators. The Kapton layer has been modified and adapted for detection purposes as shown in Figure 3. The support structure setup of SOLID takes place similar to the EURECA solar panel for at least following reasons:

- the known damage data from EURECA and HST can be used,

- easy manufacture and handling of the detector prototype (compare to HST),

- high structural stiffens. Avoidance of geometrical deviations regarding e.g. transportation and Handling of SOLID, 
- low cost,

- assumption: future solar generators will make use of electrical and thermal insulating layer (e.g. Kapton). Detection layer can be applied to it.

\subsection{Theoretical SOLID Layer Setup}

According to [8], damage on solar generator caused by impact of an incident Space Debris and Micrometeoroids can result in many different crater shapes and depths or even in a complete penetration. SOLID can detect such kind of damages, which generate large craters down to the detection layer and consequently cut the detection lines (see Figure 3 ) or penetrate the entire solar generator setup. The SOLID design considers the smallest expected damage on solar cell which fulfils these conditions. The threshold determination of the object which generates detectable damage is performed by using known damage equations described in [8]. Based on the analysis within [7] it can be stated that $700 \mu \mathrm{m}$ (thickness of upper layers of EURECA and HST) can be penetrated by ca. dp 150 $\mu \mathrm{m}$ at $21.4 \mathrm{~km} / \mathrm{s}$ and $\mathrm{dp} 300 \mu \mathrm{m}$ at $5 \mathrm{~km} / \mathrm{s}$. SOLID concept with a similar top layer setup (cover glass down to insulation layer) to EURECA or HST should be able to detect particles in this size range.

The usage of experimental damage data, which are given within [8], make it necessary to stay with the detection relevant layers dimensions close to EURECA and HST solar generator. This means that the entire thickness of the relevant layers for impact detection of SOLID S/G (see Figure 4) needs to be similar to EURECA and HST.

Figure 4 shows the SOLID setup for verification purposes at the HVI-test. The total thickness of the SOLID relevant layers for impact detection is $\sim 455 \mu \mathrm{m}$. Beginning from the top, SOLID has following setup:

- $\quad$ cover glass plate with a thickness of $\sim 100 \mu \mathrm{m}$,

- adhesive for glass cover plate DC 93500 with the thickness of $\sim 30 \mu \mathrm{m}$

- solar cells with a thickness of $150 \mu \mathrm{m}+/-20 \mu \mathrm{m}$,

- adhesive silicon rubber in-between the solar cell and the detection layer with the thickness of $\sim 70 \mu \mathrm{m}$.

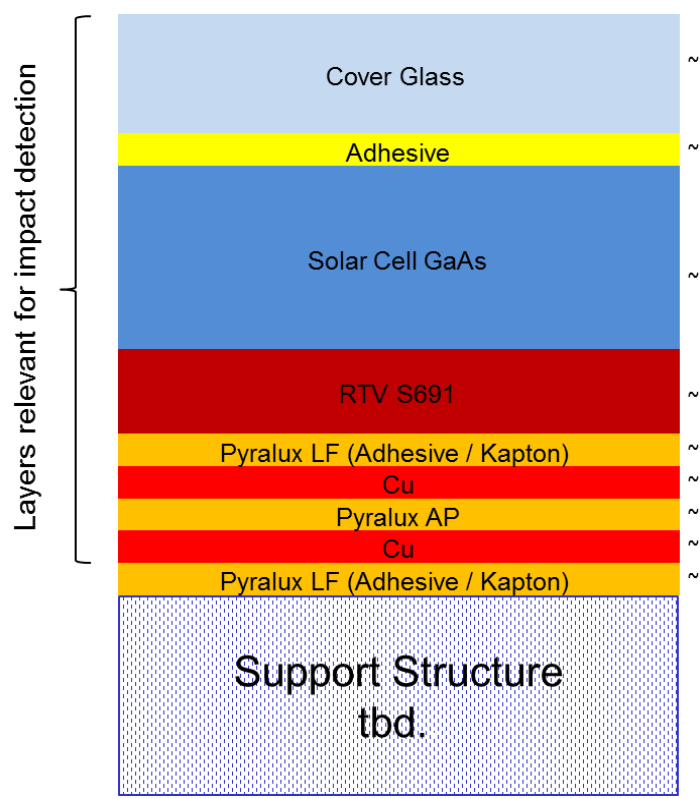

Figure 4: Detection Layer setup for HVI-test

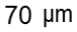

$30 \mu \mathrm{m}$ $25 \mu \mathrm{m}$ $25 \mu \mathrm{m}$ $25 \mu \mathrm{m}$ $30 \mu \mathrm{m}$
Detection layers are integrated cross-over to the polyimid film. The thickness of the individual copper array layer should be as small as possible and was set to $25 \mu \mathrm{m} \mathrm{+/-}$ $5 \mu \mathrm{m}$. This limitation is imposed by an applied manufacturing process. Small thickness of each individual layer increases the sensitivity to small damage and keeps the mass low. The used detection layer for SOLID verification is shown in Figure 4. Beginning from the top, the setup of the detection layer is:

- Pyralux LF 30 $\mu \mathrm{m}$,

- Copper $\sim 25 \mu \mathrm{m}$,

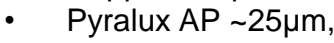

- Copper $\sim 25 \mu \mathrm{m}$,

- Pyralux LF $30 \mu \mathrm{m}$.

The entire thickness of the detection layer is $\sim 135 \mu \mathrm{m}+/$ $10 \mu \mathrm{m}$.

As mentioned above the smallest detectable damage on solar generator has a crater form. A detectable impactor generates a certain depth and cuts at least one detection line. According to $[7,8]$, Class III impact morphology is believed to fulfil this requirement. Figure 5 shows the general relationship between crater penetration depth $P$ and the corresponding pit diameter Dpit of the Class III crater. Assuming that the crater is an ellipsoid, it is possible to estimate the damage size along the semimajor axis, which describes the depth $\mathrm{P}$ of the crater. The damage in a particular level of the crater is assumed to be circular and is denoted as D. It should be noted that the crater damage form shown in Figure 5 is transformed into a penetration hole in case the conchoidal diameter Dco exceeds the threshold value.

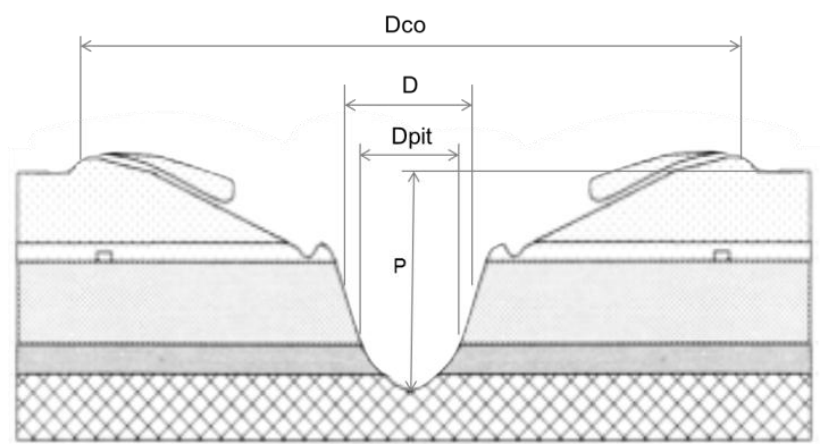

Figure 5: Class III impact morphology crater depth and diameter $[7,8]$

The classification of Class III (crater damage) and Class IV (penetration hole) damage morphologies are shown in Table 2. This assumption allows the setup of the detection layer design which is both sensitive to small damage craters and penetration holes [7].

Table 2:Impact parameter relationship [8]

\begin{tabular}{|l|c|c|c|c|}
\hline \multirow{2}{*}{} & \multicolumn{2}{|c|}{ Class III: } & \multicolumn{2}{c|}{ Class IV } \\
\cline { 2 - 5 } & HST & EURECA & HST & EURECA \\
\hline Dco [mm] & 1.82 & $1.88-2.03$ & 2.38 & 2.31 \\
\hline Dco/P & \multicolumn{2}{|c|}{$\sim 4$} & \multicolumn{2}{|c|}{$\sim 3.5$} \\
\hline Dpit/P & \multicolumn{2}{|c|}{0,25} & \multicolumn{2}{|c|}{0,7} \\
\hline
\end{tabular}

HVI-test setup of SOLID is designed with respect to 
available EURECA and HST post flight shots data. The particle diameter dp of ca. $300 \mu \mathrm{m}$ at velocity of $5 \mathrm{~km} / \mathrm{s}$ results in a Dco of ca. $2.49 \mathrm{~mm}$. This leads to Class IV damage (see Table 2) which penetrates the EURECA or the HST upper layers of ca. $700 \mu \mathrm{m}(\mathrm{P}=2.49 \mathrm{~mm} / 3.5)$. The calculated crater pit diameter Dpit is ca. $500 \mu \mathrm{m}$. Since the Class IV damage morphology results in a penetration hole it is also possible to calculate the hole diameter Dh. Based on different empirical formulas taken from [8, 9] and analysed within [7] for the given Dco of ca. $2.49 \mathrm{~mm}$ the Dh can vary between ca. $240 \mu \mathrm{m}$ and $1 \mathrm{~mm}$.

Figure 6 illustrates a section of the detection grid with the minimal expected damage diameter of ca. $240 \mu \mathrm{m}$. The detection grid comprises two detection arrays in two different levels separated by an insulation layer. The detection lines of each array are designed as $100 \mu \mathrm{m}$ wide lines with $200 \mu \mathrm{m}$ pitch distance. At least one detection line in each detection array can be assumed to be severed by $240 \mu \mathrm{m}$ damage diameter.

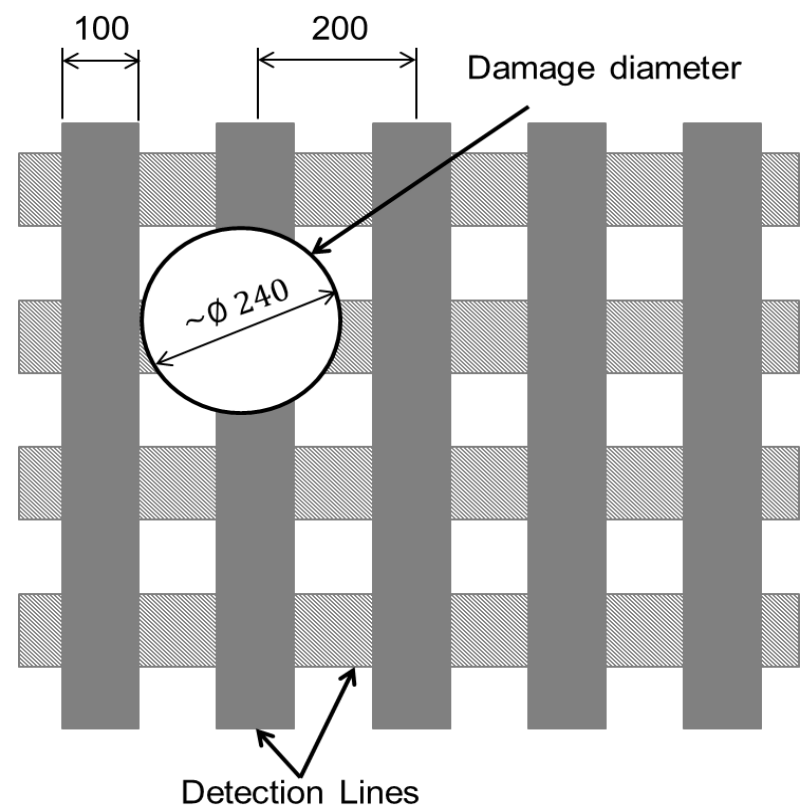

Figure 6: Crater diameter estimation

HVI testing of SOLID shall verify the concept for impact detection by using adapted solar generators of a spacecraft. Furthermore, the sensibility of the concept will be tested to determine the optimal design parameters (breadth of detection lines and pitch distance) for the detection layers.

\subsection{SOLID Manufacturing Process}

Development of SOLID can be subdivided into two main categories:

1) the Solar Generator (S/G) with integrated Detection Layers (DL) which is used as an impacting surface for impact detection as shown in Figure 3.

2) the electronics box (E-BOX) which is responsible for event identification and data acquisition as illustrated in Figure 2.

The present paper focuses on the development and manufacturing of the solar generator for impact detection purposes.
The main focus with regard to the manufacture of the SOLID lies in producing an appropriate model, to which ESA investigation on retrieved solar arrays can be applied and verified by HVI-tests. Because of cost reasons, this goal shall be reached with state of the art components and manufacturing processes. Figure 7 shows the SOLID manufacturing process steps. Initially, the Detection Layer (DL), made of polyimid, is manufactured. The detection layer is then integrated with Carbon-Fiber-Reinforced Plastic (CFRP) and subsequently with aluminium honeycomb. Afterwards, the Surface-Mounted Device (SMD) is integrated on the DL. The last step is the integration of solar cells on top of the detection layer. The blue market steps are completed or are close to finalisation. The grey step is the final phase before the manufacturing process planned completion in late 2012.

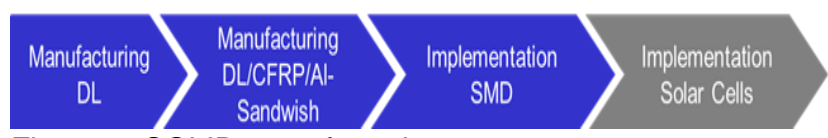

Figure 7: SOLID manufacturing process

\section{SOLID ENGINEERING MODEL}

Hereafter, the already manufactered components of SOLID are presented. Furthermore, assumptions in terms of manufacturing and $\mathrm{HVI}$-test preparation are presented and discussed.

\subsection{Manufactured Parts for SOLID Verification}

Figure 8 shows the manufactured detection layer for SOLID. The dimensions of the panel are $380 \mathrm{~mm} x$ $255 \mathrm{~mm}$. The thickness is $\sim 130 \mu \mathrm{m}+/-10 \mu \mathrm{m}$. The marked area is foreseen for implementation of solar cells and is $168 \mathrm{~mm} \times 120 \mathrm{~mm}$. The solar cells covered area is used for detection purpose. The copper line arrays of the detection layer are placed in two different planes to form a detection grid as shown in Figure 4. Electrical insulation of the copper lines in two different planes is realised by using polyimid foil Pyralux AP of $\sim 25 \mu \mathrm{m}$ thickness. The manufactured width of the detection lines is $100 \mu \mathrm{m}$ and the array spacing is $200 \mu \mathrm{m}$. The top and bottom side of the detection layer is covered by polyimide foil Pyralux LF $\sim 30 \mu \mathrm{m}$ for electrical insulating purpose of the conductive copper lines.

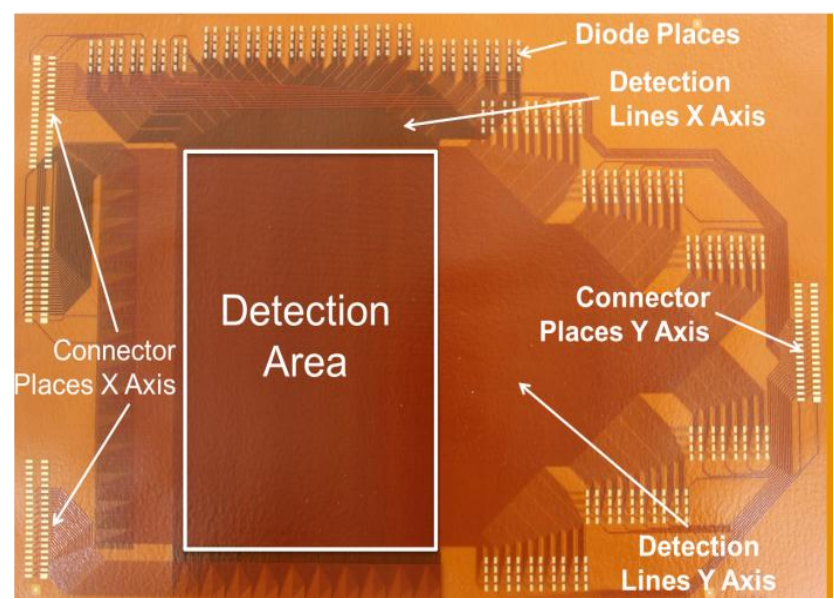

Figure 8: Detection Layer for SOLID 
The solar cells covered detection area comprises $840 x$ 600 detection lines. The determination of impact location and damage size requires a clear interpretation of each single detection line by the electronics box. Figure 9 shows the X-axis array. For the HVI-test each detection line is protected by a diode to avoid ambiguous results. The chosen diodes for the HVI-test have a larger pin pitch than the detection line pitch by factor of 2.5. This makes it impossible to integrate the diodes in line with the detection copper lines as shown in Figure 9. The detection lines needs to be widened to the pitch of the diode to be able to integrate all necessary diodes. This leads to a larger detection layer as shown in Figure 8.

The decision to use these diodes has been driven by cost. In the case of spacecraft application the design can be made more compact as shown in Figure 9 by using diodes suitable in breadth and height for the detection grid.

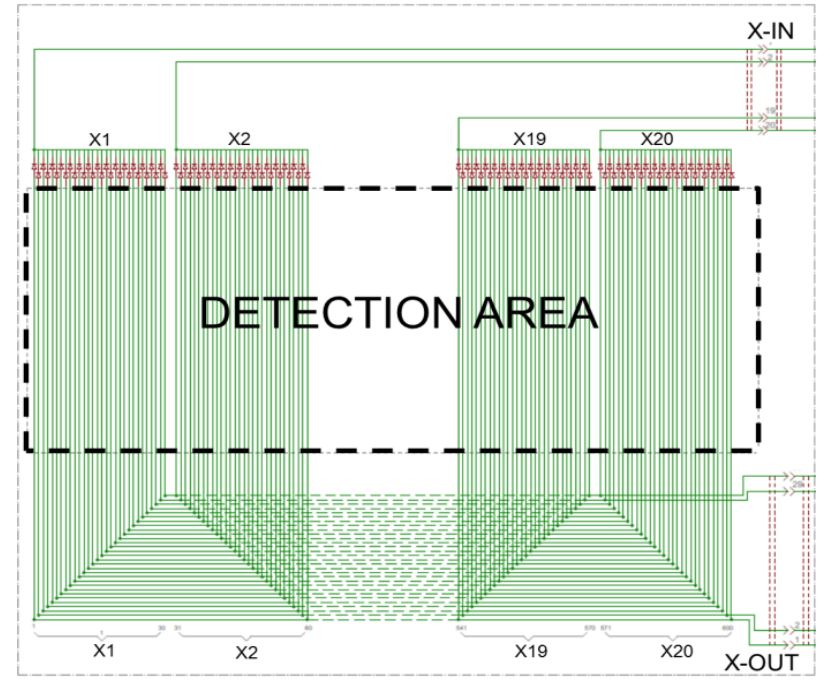

Figure 9: Schematic circuit diagram for $\mathrm{X}$-axis

Figure 10 shows the SOLID detection layer, which is applied to Carbon-Fiber-Reinforcedm Polymer (CFRP) / Aluminium honeycomb.

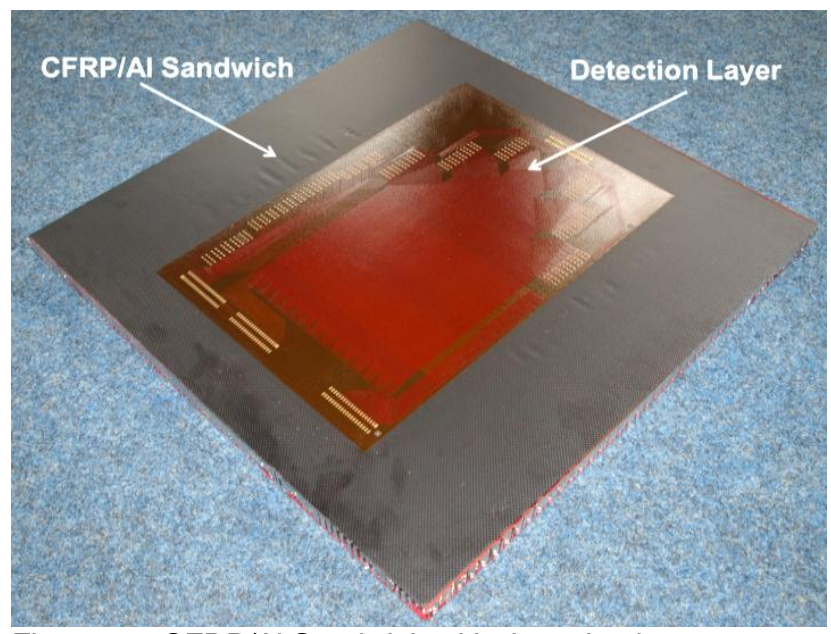

Figure 10: CFRP/AI Sandwich with detection layer

The dimensions of the CFRP/Al sandwich are $450 \mathrm{~mm} x$ $450 \mathrm{~mm}$. The assembling of the detection layer to the CFRP was performed by using an autoclave manufacturing process. To be able to use the data from the ESA reports $[8,9]$, prepreg with a mass-area ratio of $93 \mathrm{~g} / \mathrm{m}^{2}$ was used. In a cured condition, the CFRP face sheet thickness of the SOLID is comparable to the face sheet thickness of EURECA of $\sim 100 \mu \mathrm{m}$. The applied aluminium honeycomb has a cell size of $1 / 4$ " and height of $22 \mathrm{~mm}$. Figure 11 illustrates the implemented Surfacemounted device (SMD) on the detection layer. As mentioned before, every detection line is protected by a diode. The diodes used for SOLID verification at HVItesting are CM1213 from ON Semiconductor. The SMD implementation of the detection layer takes place by using state of the art SDM implementation processes. The integration of the connectors is done at DLR.

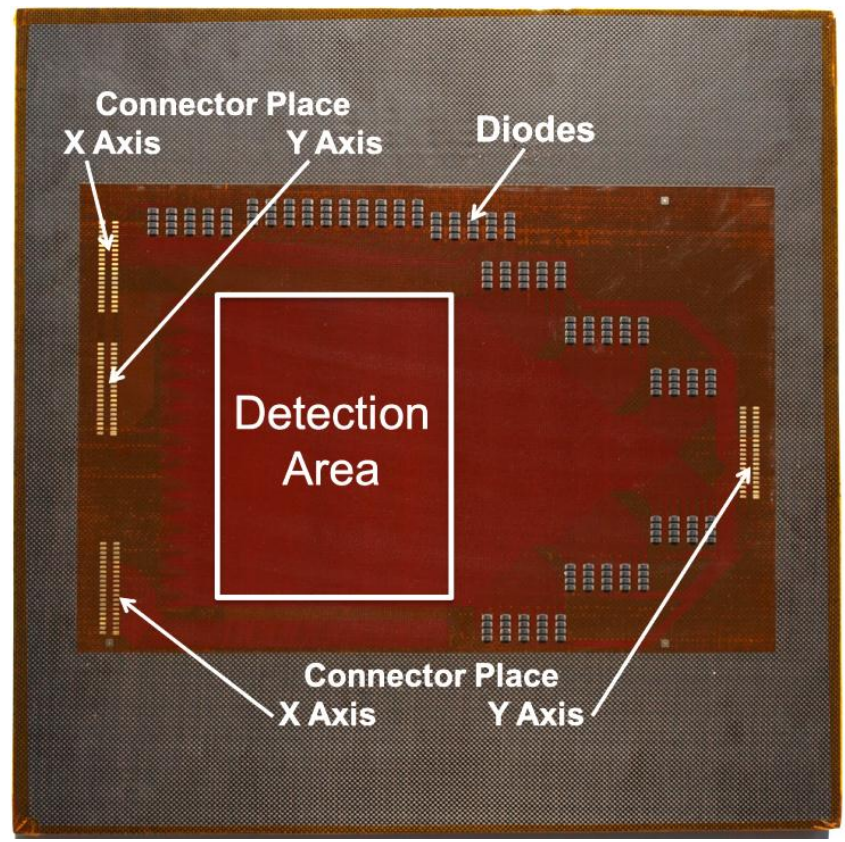

Figure 11: SMD Implementation

SOLID verification will be performed with triple junction (TJ) solar cells $3 G 28 \mathrm{C}$ from AZUR SPACE. The dimensions of the solar cell are $40 \mathrm{~mm} \times 80 \mathrm{~mm}+/-0.1 \mathrm{~mm}$ and the thickness is $150 \mu \mathrm{m}+/-20 \mu \mathrm{m}$. The outstanding implementation of solar cells to the detection layer will be done in autumn 2012.

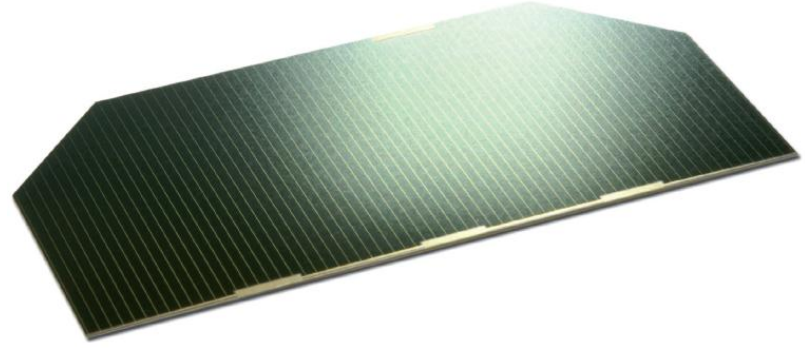

Figure 12: Triple Junction solar cell Photo Azur Space [10]

\section{HVI-TEST PLANNING}

Simultaneous with the manufacturing of the SOLID components, the planning of the High Velocity Impact test (HVI-test) takes place at the DLR in Bremen. The HVItests are planned for winter 2012 and will be performed at the Fraunhofer EMI (Ernst-Mach-Institute for High-Speed Dynamics in Freiburg, Germany). The experimental HVItest setup and results will be discussed in a follow-up paper. 


\section{CONCLUSION}

Space Debris or Micrometeoroid impacts can lead to the degradation of a spacecraft or payload or even to the loss of the mission. Software models e.g. MASTER, ORDEM can be used to analyse this risk potential. The analysis should be made in the early design phases to be able to integrate all required shielding to the spacecraft and to consider them within e.g. the mass budget. The environmental models use measured data from ground and space based systems to describe the environment. Nevertheless, the measured data is limited especially in sub $\mathrm{cm}$ size range. In terms of risk reduction of future space missions, the environmental models (e.g. MASTER, ORDEM) needs to be validated by measured data. For this purpose the Solar Genarator based Space Debris Impact-Detector (SOLID) concept is proposed, which is currently under development at DLR Institute of Space Systems. SOLID has a large impact area and offers high orbital flexibility regarding data acquisition for environmental model validation purposes. The verification of the SOLID concept itself will be done at Fraunhofer EMI (Ernst-Mach-Institute for High-Speed Dynamics in Freiburg, Germany). To be able to use the damage data from ESA investigations on retrieved solar generators from space, the engineering of SOLID is oriented on EURECA and HST solar panels. This paper presents the design of the detector as well as of some already manufactured ground test elements. Furthermore, the assumptions in terms of manufacturing of the SOLID engineering model are presented and discussed. The setup of the HVI-test and the according test results will be published in followup papers.

\section{ACKNOWLEDGMENT}

The work was funded by DLR (Deutsches Zentrum für Lüft- und Raumfahrt) in the frame of research programme of SARA (System Analysis Space Segment). The contribution to the design of the detection layer by Alexei Pissarskoi (DLR Bremen, Germany) is gratefully acknowledged.

\section{REFERENCES:}

[1] Flegel S. Maintenance of the ESA MASTER Model, Final Report, 2011

[2] Wiedemann, C., Space Debris - Current Situation, DGAP-Projektgruppe Internationale Weltraumpolitik, Berlin, 2012

[3] Klinkrad, H., Space Debris Models and Risk Analysis, Springer 2006

[4] Drolshagen, G., Impact effects from small size meteoroids and space debris. Advances in Space Research, 41 (7), 1123-1131, 2008

[5] Drolshagen, G., Post-flight impact studies of solar cells retrieved from space, DLR Bremen, Institute seminar, February .2012

[6] Bauer, W., Romberg, O., 2011, Solargenerator für Raumfahrzeuge und Satelliten, Patent application, DLR57960DE

[7] Bauer, W., Romberg, O., Wiedemann C., Drolshagen G., Vörsmann P., Advances in Space Research, to be published in 2012

[8] McDonnell, J.A.M. (Ed.),Meteoroid and debris flux and ejecta models, Final and Summery Reports of
ESA, Contract No.11887/96/NL/ JG, Unispace Kent,Canterbury, UK, 1998

[9] McDonnell, J.A.M. (Ed.) Post-Flight Impact Analysis of HST Solar Arrays - 2002. Retrieval, Final Report of ESA, Contract No.16283/02/NL/LvH, UK, 2002

[10] AZUR SPACE Solar Power $\mathrm{GmbH}$, Data sheets space, 16.08.2012 azurspace.. de/index.php?page=93Dew 